\title{
Surface Quality after Grinding VACO 180 Tool Steel using Different Cutting Conditions
}

Tomas Baksa, Jindrich Farsky, Ondrej Hronek, Miroslav Zetek

Faculty of Mechanical Engineering, University of West Bohemia. Univerzitni 8, 30614 Pilsen. Czech Republic. E-mail: baksa@rti.zcu.cz, farskyj@rti.zcu.cz,hroneko@rti.zcu.cz,mzetek@rti.zcu.cz

This paper is focused on research in the field of grinding VACO 180 tool steel. Different grinding conditions in terms of several cutting speeds and depths of cut were used for grinding tool steel with CBN grinding wheels. Two CBN grinding wheels with different grain sizes were used for several tests with the same grinding strategy. The influence of the cutting speed and depth of cut on the surface roughness was observed. The different behaviour of both grinding wheels was found during grinding in terms of achieved surface roughness. Higher grain size of the grinding wheel led to higher surface roughness, which increased with cutting speed. However, grinding with deeper cuts showed the opposite effect, and the surface roughness was better at higher cutting speeds. Lower grain size gave a more stable grinding process in terms of achieved surface roughness and lower influence of the cutting speed. However, greater wheel wear occurred during grinding with greater depth of cut. The grinding wheel was dressed before each test to ensure the same grinding ability. The results of this work will be used for a better understanding of the process of grinding tool steel.

Keywords: Grinding, Cutting conditions, Roughness, Tool steel

\section{Introduction}

There are many different tool materials on the market which are used in many engineering applications. Tool steels are used because of their significant hardness, and resistance to abrasion and deformation. They are also able to keep a sharp cutting edge at higher temperatures. Tool steel VACO 180 is high strength, martensitic hardened steel which has an optimum combination of very high tensile strength and toughness. This steel is used for mechanically stressed tools such as dies for cold forming, separators or die casting moulds. Higher demands on the quality of mechanical parts lead to higher demands on the production of the parts.

Mechanical parts made of tool steel are commonly processed by conventional machining such as milling or turning. Choosing the right technology and cutting tool depends on the required shape, precision, surface quality and heat treatment of the machined part. Carbide cutting tools are widely used for machining tool steel in the form of solid cutting tools or cutting inserts. However, the surface roughness after turning or milling is limited and it is very difficult to achieve high surface quality.

Another finishing operation such as grinding is necessary if high surface quality of the part is required. During grinding the material is removed by geometrically undefined cutting edges (abrasive grains). Grinding is characterized by higher specific energy which is largely changed into heat. The impact of the cutting parameters on the grinding temperature is described in [1]. The accumulation of heat could lead to severe thermal damage on the ground surface. The surface integrity and roughness after grinding stainless steel was investigated in [2]. Therefore, it is necessary to choose an appropriate grinding wheel and coolant to ensure a stable and effective grinding process. The effect of different types of coolants and flowrates on the grinding process is described in [3, 4].

Conventional abrasives such as corundum or silicon carbide are commonly used for grinding steel. An advantage of corundum grinding wheels is their low cost. However, the wheel wear during grinding is relatively high, which leads to frequent truing of the grinding wheel. For profile grinding wheels, truing is lengthy and expensive. Relatively high wheel wear also occurs when using silicon carbide $(\mathrm{SiC})$ grinding wheels, however $\mathrm{SiC}$ wheels do not need a diamond dresser for truing, unlike corundum wheels.

Diamond grinding wheels, which belong to the group of super-abrasives, are not suitable for grinding steel due to their chemical affinity with this material, which leads to sticking of the material chips on the grinding wheel. CBN grinding wheels are used for productive grinding of hard steels such as high speed steel. Compared to diamond wheels, CBN abrasives have no chemical affinity with the ferriferous component of the material. The high wear resistance of CBN grinding wheels leads to higher durability, which is important for keeping the shape of the grinding wheel for a long time. The resulting surface depends on the grain size of the grinding wheel. The small grains are immersed deeply in the vitrified bond, resulting in a very smooth tool topography, which is reflected on the workpiece surface [5].

To achieve high quality of the ground surface we must first ensure a suitable and stable grinding process. This is done by choosing an appropriate grinding wheel and cutting conditions. A grinding process with inappropriate cutting conditions could lead to higher surface roughness and residual tensile stress on the surface, which may cause micro-cracks and reduce the fatigue life of the components. The subsurface residual stress of ground tool steel has been measured in research [6]. The basic parameter of the cutting conditions is the cutting speed, which is determined by the diameter of the grinding wheel and the spindle speed. The cutting speed in combination with other cutting parameters, such as depth of cut and feed rate, has a significant impact on the productivity and qual- 
ity of grinding. Varying combinations of cutting conditions were tested in terms of their influence on surface roughness in [7]. The depth of cut and grinding wheel dimensions determine the contact area between the grinding wheel and the workpiece and determine the volume of the material removed during the pass [8]. Theoretical analysis of the contact area was carried out in [9]. A deeper cut would also lead to a larger contact zone between the grains and the material and increase the distinct modified areas under the surface [10]. This paper deals with experimental grinding of VACO 180 tool steel to determine the influence of the cutting conditions on the surface roughness after grinding.

\section{Grinding experiment}

Experimental grinding of VACO 180 tool steel was carried out with two different $\mathrm{CBN}$ grinding wheels under different grinding conditions. The main aim of this experiment was to observe the influence of different cutting speeds and depths of cut on the resulting ground surface in terms of surface roughness. The difference in grinding wheels was their grain size and basic dimensions. Tab. 1 shows the parameters of both grinding wheels. The different widths of the grinding wheels has no influence on the grinding experiment because of the small width of the workpiece $(5 \mathrm{~mm})$, which ensures the same real grinding width for both grinding wheels. The different diameter of the wheels causes different lengths of the contact arc between the grinding wheel and the workpiece during grinding. However, this difference is insignificant due to the small depth of cut.

The ground material was in the form of a flat bar with a length of $180 \mathrm{~mm}$ and width of $5 \mathrm{~mm}$. VACO 180 steel is high strength martensitic steel with optimal tensile strength and toughness. The quality of the steel is equivalent to DIN X3NiCoMo 1895 . The chemical composition of the steel is shown in Tab. 2. The tested material was in an annealed state during grinding, but it can be hardened to 54 to $56 \mathrm{HRC}$. The mechanical properties of the steel are shown in Tab. 3.

Tab. 1 Grinding wheel parameters

\begin{tabular}{|c|c|c|c|c|c|c|}
\hline Wheel & Wheel shape & Diameter $[\mathbf{m m}]$ & Width $[\mathbf{m m}]$ & Abrasive & Bond & Grain size \\
\hline A & $1 \mathrm{~A} 1$ & 75 & 8 & CBN & Resin-bond & D64 \\
\hline B & $1 \mathrm{~A} 1$ & 100 & 6 & CBN & Resin-bond & D20 \\
\hline
\end{tabular}

Tab. 2 Chemical composition of VACO 180 tool steel

\begin{tabular}{|c|c|c|c|c|c|}
\hline C [\%] & Co [\%] & Mo [\%] & Ni [\%] & Ti [\%] & Other \\
\hline$<0.03$ & 9.0 & 5.0 & 18.5 & 0.75 & $\mathrm{Al}, \mathrm{B}, \mathrm{Zr}$ \\
\hline
\end{tabular}

Tab. 3 Mechanical properties of VACO 180 in annealed state

\begin{tabular}{|c|c|c|c|c|c|}
\hline $\begin{array}{c}\text { Yield strength } \\
{[\mathbf{M P a}]}\end{array}$ & $\begin{array}{c}\text { Tensile } \\
\text { strength [MPa] }\end{array}$ & $\begin{array}{c}\text { Ductility } \\
{[\%]}\end{array}$ & Concentration [\%] & Notch toughness [J] & Hardness HV \\
\hline 640 & 930 to 1130 & 12 & 60 & 55 & $<350$ \\
\hline
\end{tabular}

Tab. 4 Cutting conditions

\begin{tabular}{|c|c|c|c|}
\hline Wheels & $\begin{array}{c}\text { Feed rate } \\
{[\mathbf{m m} / \mathbf{m i n}]}\end{array}$ & $\begin{array}{c}\text { Grinding } \\
\text { fluid }\end{array}$ & Strategy \\
\hline A, B & $?$ ? & Mineral oil & $\begin{array}{c}\text { Down } \\
\text { grinding }\end{array}$ \\
\hline Test & $\begin{array}{c}\text { Cutting speed } \\
\text { vc [m/s] }\end{array}$ & $\begin{array}{c}\text { Depth of cut } \\
\text { [mm] }\end{array}$ \\
\hline T1 & 25 & 0.05 \\
\hline T2 & 30 & 0.05 \\
\hline T3 & 35 & 0.05 \\
\hline T4 & 25 & 0.1 \\
\hline T5 & 30 & 0.1 \\
\hline T6 & 35 & 0.1 \\
\hline T7 & 25 & 0.2 \\
\hline T8 & 30 & 0.2 \\
\hline T9 & 35 & 0.2 \\
\hline
\end{tabular}

Grinding was performed on a CNC 5-axis tool grinder with high precision. The test bar was clamped into the clamping system which ensured its steady position during grinding. The top face of the steel bar was ground during each test by the periphery of the wheel using down grinding strategy to ensure better stability of the grinding process. The strategy of the grinding is shown in Fig. 1. Several tests were performed with both $\mathrm{CBN}$ grinding wheels under different cutting conditions in terms of different cutting speeds and depths of cut. The feed rate was constant for all the tests. Tab. 4 shows all the testing variants of the cutting conditions. High-performance grinding fluid was used during grinding to ensure better lifetime of the grinding wheel and stability of the grinding process.

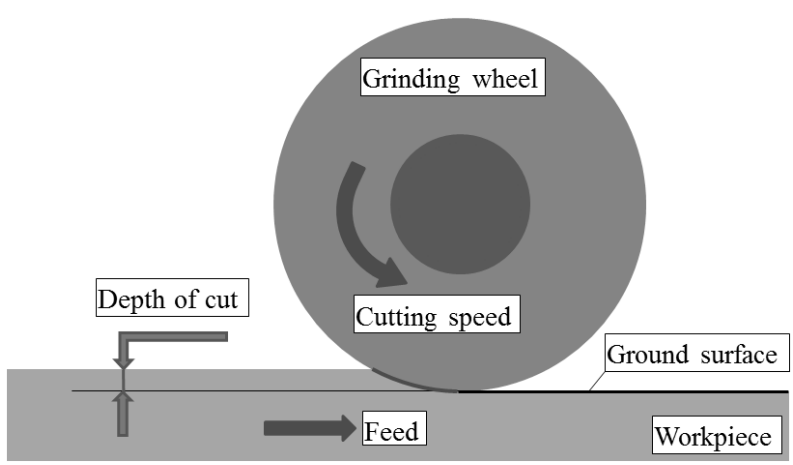

Fig. 1 Grinding strategy

\section{Measurement and analysis}

VACO 180 tool steel was ground under different cutting conditions using two different $\mathrm{CBN}$ grinding wheels. Both grinding wheels were dressed before each test to stop the wheel clogging and ensure the same initial grinding ability of the wheels. The dressing was done using an aluminium oxide stick with two different grain sizes 
which are suitable for each grinding wheel. Each test consisted of 3 passes with specified cutting conditions. The first pass was to stabilise the sharp grinding wheel after dressing. The next two passes were testing passes to determine the influence of the grinding on the ground surface. The ground surface was measured after three passes using an optical-scanning device. The surface was scanned at three locations to observe the change of the roughness during the passes. The roughness was evaluated in terms of the arithmetical mean deviation of the roughness profile $(\mathrm{Ra})$ and the maximum height of the roughness profile $(\mathrm{Rz})$. The measurement was carried out perpendicular to the grinding marks. The grinding of VACO 180 with grinding wheel A was characterized by variable roughness depending on the varied cutting conditions. The surface roughness linearly increased with cutting speed during tests T1A to T3A with depth of cut of $0.05 \mathrm{~mm}$. The same effect occurred with a deeper cut of $0.1 \mathrm{~mm}$ during tests T4A to T6A. However, the depth of cut of $0.1 \mathrm{~mm}$ was characterized by a slightly better surface roughness than the depth of cut of $0.05 \mathrm{~mm}$. In addition, test T6A showed a similar surface roughness as test T5A with a lower cutting speed. When the depth of cut was increased again to $0.2 \mathrm{~mm}$ during grinding with grinding wheel A, the cutting speed had the opposite effect compared to the previous tests. The highest roughness was measured after test T7A with the deepest cut and the lowest cutting speed. As the cutting speed increased during tests T8A and T9A, the surface roughness decreased (Fig. 2).

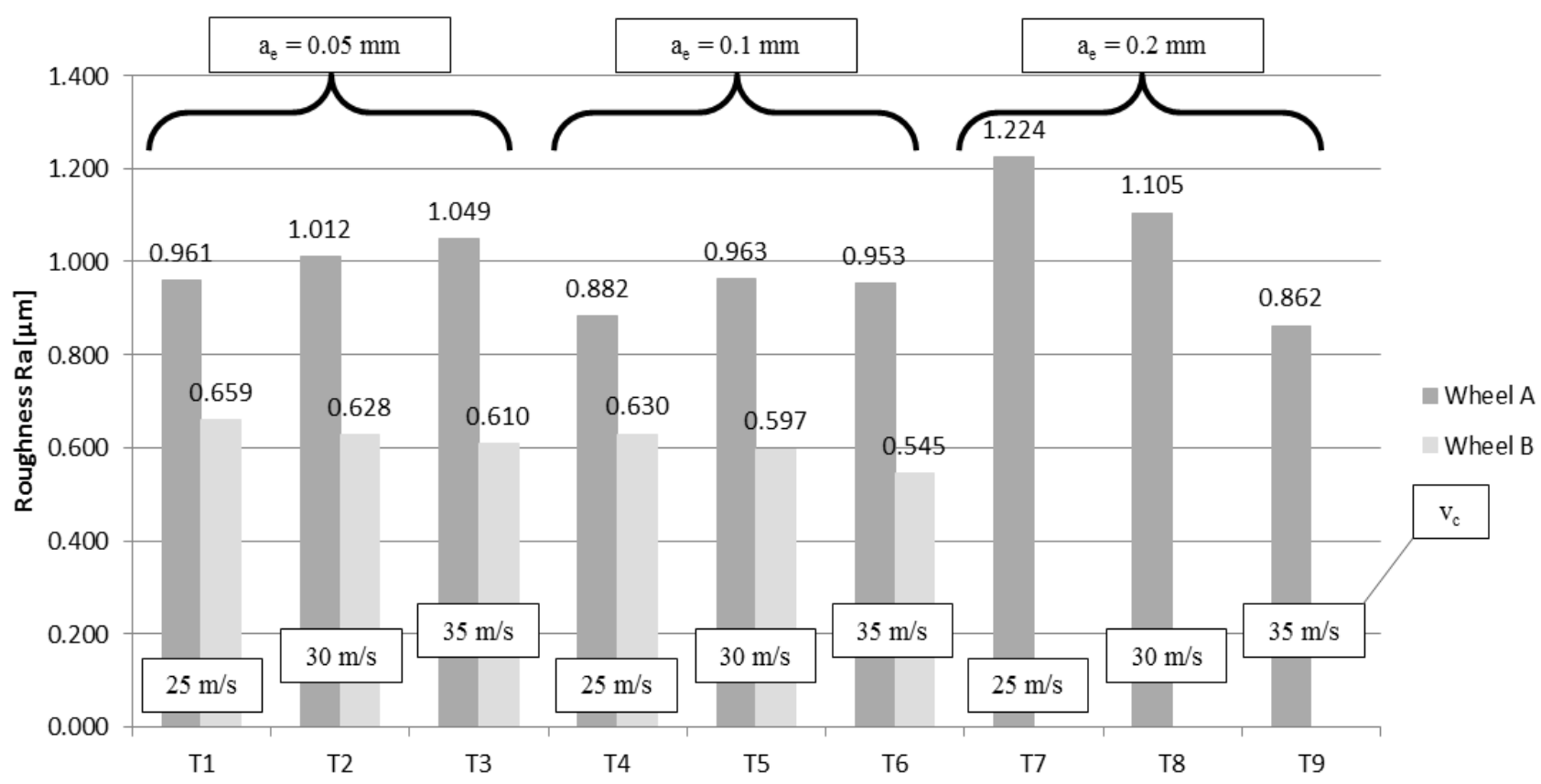

Fig. 2 Surface roughness after grinding $R a$

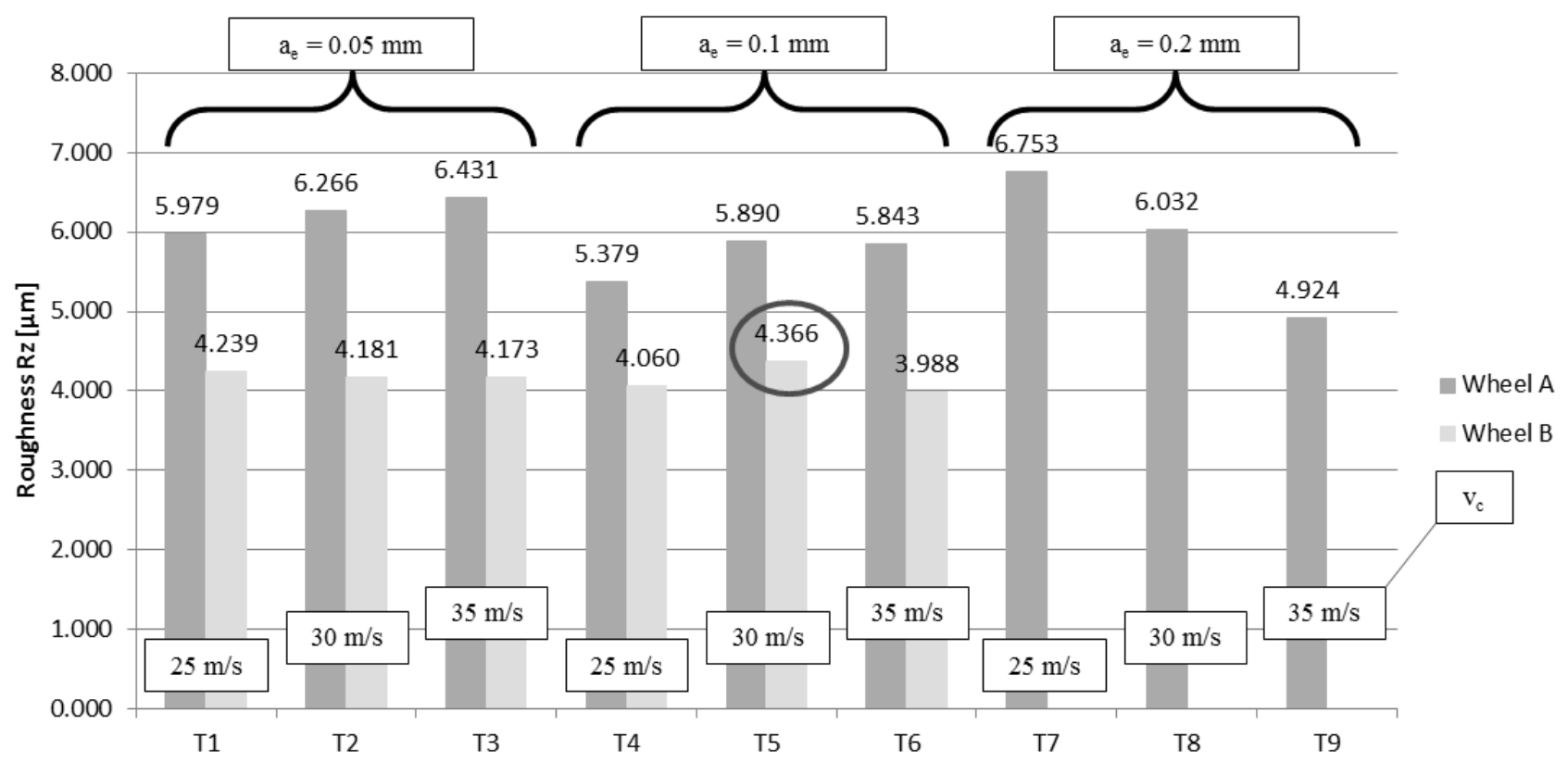

Fig. 3 Surface roughness after grinding $R z$ 
Grinding wheel B was used for grinding tool steel with the same cutting conditions as wheel A. This grinding wheel was characterized by small grain size, suitable for finishing operations to achieve low surface roughness. Grinding with wheel B was characterized by lower surface roughness after grinding than with wheel $A$. The highest surface roughness was measured after test T1B, characterized by low depth of cut and low cutting speed. The surface roughness slightly decreased with increasing cutting speed in tests T2B and T3B. The same effect occurred with a deeper cut of $0.1 \mathrm{~mm}$ between tests T4B and T6B. However, the difference in the surface roughness during tests with wheel B was very small compared to grinding wheel A. In addition, high wheel wear occurred during grinding with wheel B. Even more wheel wear occurred when the depth of cut was increased to $0.1 \mathrm{~mm}$, which caused more than double the wheel wear compared to the lower depth of cut. The grinding experiment with wheel B was ended after test T6B due to this intense wheel wear. It is assumed that increasing the depth of cut to $0.2 \mathrm{~mm}$ would cause more significant wheel wear, which could lead to damage of the grinding wheel. The best result in terms of surface roughness $\mathrm{Ra}$ and $\mathrm{Rz}$ was achieved during test $\mathrm{T} 6 \mathrm{~B}$ with the highest cutting speed and the middle depth of cut with grinding wheel B. Test T5B also achieved very good results for Ra roughness, but the worst result for $\mathrm{Rz}$ roughness for grinding wheel B (fig. 3).

Different surface roughnesses can be observed visually on the ground surface. The higher roughness achieved using wheel A was characterized by stronger grinding marks. As the surface roughness decreases, the grinding marks become smoother (Fig. 4)
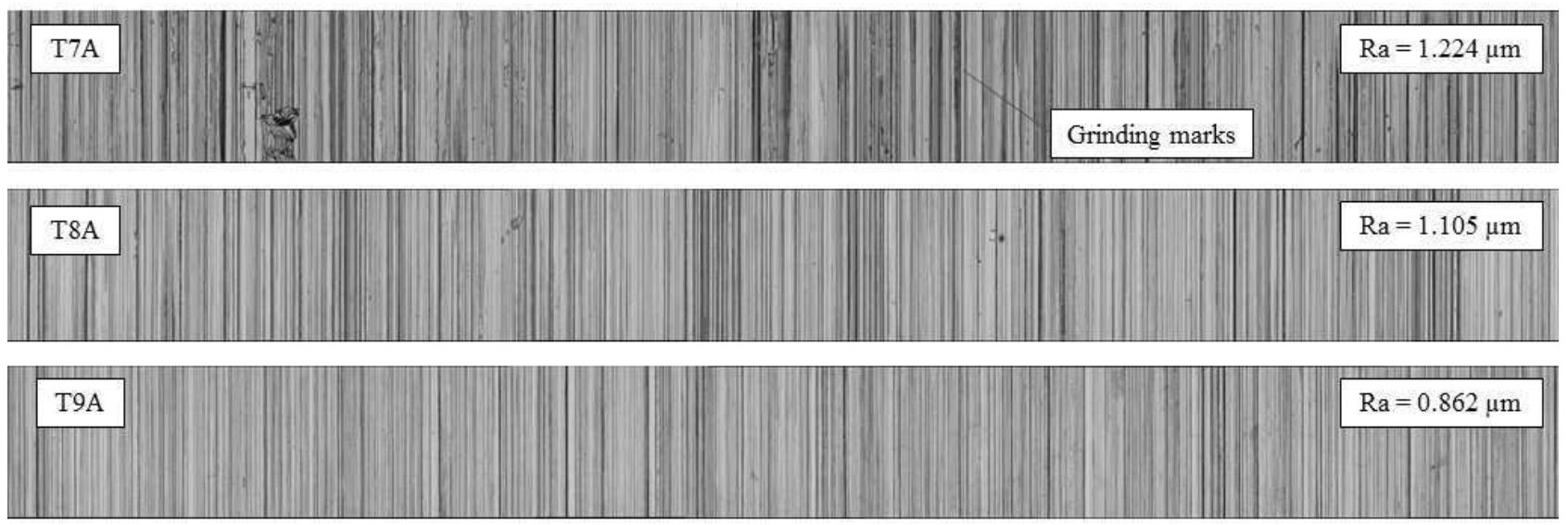

Fig. 4 Surface after grinding with grinding wheel A

Grinding with grinding wheel B was characterized by significant scratches on the surface compared to wheel A (Fig. 5). The most significant scratches occurred after grinding at the lowest cutting speed and the deepest cut (T4B). Higher cutting speed and lower depth of cut led to less scratch formation (T3B). It is assumed that these scratches and deformation marks occurred due to rubbing between the grinding wheel and the ground material. A combination of small grain size, higher depth of cut and lower cutting speed leads to too much material being removed per one rotation of the grinding wheel. The removed material starts to smudge, which can load the grinding wheel and decrease its grinding ability. This can also be the cause of high wheel wear.
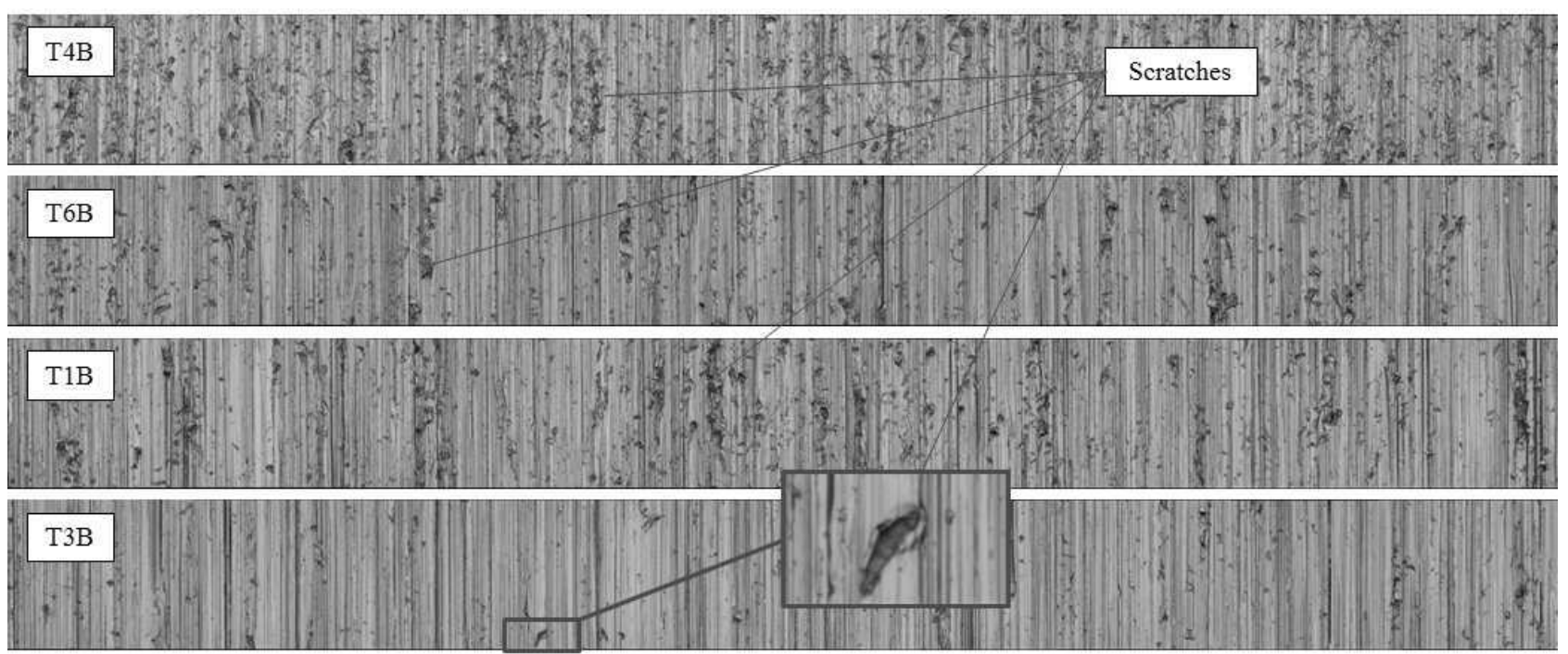

Fig. 5 Surface after grinding with grinding wheel B 


\section{Conclusion}

This article deals with the influence of different cutting conditions on the grinding of VACO 180 tool steel. Two CBN grinding wheels with different grain sizes were used for experimental grinding under different grinding conditions. The experiment was composed of several tests with different combinations of cutting speeds and depths of cut. The main aim was to determine the influence of these conditions on the quality of the ground surface in terms of surface roughness. Other cutting conditions were constant. Each test included three passes of a defined length. Both grinding wheels were dressed between each test to ensure the same grinding ability. It was found that the depth of cut and cutting speed have a significant influence on the surface roughness after grinding with wheel A (bigger grain size). Roughness increased with cutting speed for depths of cut of $0.05 \mathrm{~mm}$ and 0.1 $\mathrm{mm}$. However, the cutting speed had the opposite effect when the depth of cut increased to $0.2 \mathrm{~mm}$. It seems that better surface roughness can be achieved by lower cutting speed with low depth of cut, or by higher cutting speed with deeper cuts. The cutting conditions had little influence on the surface roughness when grinding wheel B (small grain size) was used. It was found that higher cutting speed leads to slightly better surface roughness with depths of cut of $0.05 \mathrm{~mm}$ and $0.1 \mathrm{~mm}$. However, greater depths of cut caused significant wheel wear, therefore the test with depth of cut of $0.2 \mathrm{~mm}$ was not carried out. In general, grinding wheel B achieved lower surface roughness than wheel A, which was expected. However, scratch formation occurred on the ground surface during grinding with wheel $\mathrm{B}$. The scratch formation was reduced by increasing the cutting speed. The results of this work will be used for further study of the process of grinding VACO 180 tool steel.

\section{Acknowledgement}

This work has been prepared under project $\mathrm{LO} 1502$ 'Development of the Regional Technological Institute' under the auspices of the National Sustainability Programme I of the Ministry of Education of the Czech Republic aimed at supporting research, experimental development and innovation.

\section{References}

[1] KOCMAN, K. (2014). Influence of the Thermodynamic Phenomena on the Optimum Cutting Parameters in Grinding. In: Manufacturing Technology, Vol. 14, No. 1, pp. 34 - 41. ISSN 12132489.

[2] ZHOU, N., PENG, R. L., PETTERSSON, R. (2016). Surface integrity of 2304 duplex stainless steel after different grinding operations. In: Journals of Materials Processing Technology, Vol. 229, pp. 294 - 304. ISSN: 0924-0136.

[3] MANIMARAN, G., KUMAR, M. P., VENKATASAMY, R. (2014). Influence of cryogenic cooling on surface grinding of stainless steel 316. In: Cryogenics, Vol. 59, pp. $76-83$. ISSN: 0011-2275.

[4] LAVISSE, B., LEFEBVRE, A., TORRANCE, A. A., SINOT, O., HENRION, E., LEMARIE, S., TIDU, A. (2018). The effects of the flow rate and speed of lubricoolant jets on heat transfer in the contact zone when grinding a nitrided steel. In: Journal of Manufacturing Processes, Vol. 35, pp. 233 - 243. ISSN: 1526-6125.

[5] DENKENA, B., GROVE, T., LUCAS, H. (2016). Influences of grinding with Toric CBN grinding tools on surface and subsurface of 1.3344 PM steel. In: Journals of Materials Processing Technology, Vol. 229, pp. 541 - 548. ISSN: 09240136.

[6] XIAO, K. Q., ZHANG, L. C. (2006). The effect of compressed cold air and vegetable oil on the subsurface residual stress of ground tool steel. In: Journals of Materials Processing Technology, Vol. 178, pp. 9 - 13. ISSN: 0924-0136.

[7] NOVAK, M. (2012). Surface with high precision of roughness after grinding. In: Manufacturing Technology, Vol. 12, No. 12, pp. 66 - 70. ISSN 1213-2489.

[8] BAKSA, T., FARSKY, J., HRONEK, O., ZETEK, M. (2018). Influence of Depth of Cut on Quality of Ground Surface and Cutting Force when Grinding Cermet. In: Manufacturing Technology, Vol. 18, No. 3, pp. 352 - 356. ISSN 12132489.

[9] KUNDRAK, J., FEDOROVICH, V., PYZHOV, I., MARKOPOULOS, A. P., KLIMENKO, V., KRYUKOVA, N. (2017). Theoretical Analysis of the Contact Area between Grinding Wheel Surface and Workpiece in Flat Face Grinding with Spindle Axis Inclination. In: Manufacturing Technology, Vol. 17, No. 2, pp. 203 - 210. ISSN 12132489.

[10] HEINZEL, C., BORCHERS, F., BERGER, D., EHLE, L. C. (2016). Surface and material modifications of tempered steel after precision grinding with electroplated coarse grained diamond wheels. In: Procedia CIPR, Vol. 45, pp. 196 - 194. ISSN: 2212-8271. 